\title{
A large posterior vaginal wall cyst simulating rectocele: an account of an unusual perplexing case
}

\author{
Deepali Garg, Sheeba Marwah*, Ritu Sharma, Sudha Salhan
}

Department of Obstetrics and Gynecology, NDMC Medical College and Hindu Rao Hospital, Delhi, India

Received: 17 January 2018

Accepted: 01 February 2018

\section{*Correspondence:}

Dr. Sheeba Marwah,

E-mail: sheebamarwah@yahoo.co.in

Copyright: (C) the author(s), publisher and licensee Medip Academy. This is an open-access article distributed under the terms of the Creative Commons Attribution Non-Commercial License, which permits unrestricted non-commercial use, distribution, and reproduction in any medium, provided the original work is properly cited.

\begin{abstract}
Benign cystic lesions of the vagina are uncommon, often being an asymptomatic incidental finding revelled during routine gynaecological examination. Large vaginal wall cysts $>5 \mathrm{~cm}$ size are a rare gynaecological entity. Most of the work available in literature accounts their mullerian genesis. Large epidermal inclusion cysts are further rarer. Thus, here is described a case illustrating an exceptional case of large epidermal inclusion vaginal wall cyst mimicking rectocele. Also, clinical considerations and relevant literature review on the same has been addressed. A 40 year old lady P2L2 presented in gynecology OPD with complaints of feeling of fullness in the vagina associated with some mass protruding out of the vagina for last few years. Careful evaluation indicated it to be a large posterior vaginal wall cyst 7x6 cm, aping enterocele, lying separate from rectum. The cyst was then surgically excised without any intraoperative or postoperative complications. Giant vaginal cysts are an uncommon occurrence. Meticulous clinical evaluation, bolstered with pertinent investigations can help in clinching the diagnosis early.
\end{abstract}

Keywords: Epidermal inclusion cyst, Perplexing case, Rectocele, Vaginal cyst

\section{INTRODUCTION}

Benign cystic lesions of vagina are frequently detected on routine gynaeco-urological examination. ${ }^{1}$ Its prevalence being 1 in 200 cases, is often underestimated, since most of the times it is left unreported because of its asymptomatic nature., ${ }^{2,3}$ They commonly afflict women in third and fourth decade of life. ${ }^{1-4}$

True cystic lesions of vagina stem from vaginal tissue only, differentiating from those of urethra and surrounding tissue. Vaginal cysts are categorized in accordance with the histopathological characteristics of lining epithelium and histochemical staining. ${ }^{5-7}$

Mostly, such vaginal cysts are very small and asymptomatic; but larger cysts cause vaginal pressure or heaviness and protrusion of mass outside the vagina. ${ }^{1,6}$ Anterior giant cysts might also cause urinary complaints like stress incontinence or obstructive voiding symptoms. Secondary infection in such cysts may also lead to pelvic pain, dyspareunia, dysmenorrhoea, vaginal discharge, bleeding or dyschezia. ${ }^{8,9}$

Thorough clinical evaluation, followed by Ultrasonography, MRI and defecography, would reveal the exact number, size and anatomical extent of the cyst, guiding in planning of appropriate surgeries. However, final diagnosis is confirmed only after histopathological study of excised tissue. ${ }^{10,11}$

There is a paucity of cases illustrating large vaginal inclusion cysts in literature, most of them being western reports. ${ }^{1-11}$ Thus, the present article describes a case with a giant posterior vaginal wall cyst that posed a dilemma in the mind of treating gynecologists due to its presenting symptoms. The critical appraisal of the accessible data 
and account of varied facets of such cysts have also been provided.

\section{CASE REPORT}

A 40 year old female, P4L4, presented in gynaecological OPD with complaints of feeling of vaginal pressure and fullness for the last 13 years and some mass protruding out of vaginum since last 8 years. The complaints were insidious in onset.

Initially the mass was small (lemon size) felt during internal examination only. However, it gradually increased to present size $\sim 7 \times 5 \mathrm{~cm}$ visible outside the vagina, especially on defecation, or coughing and straining. It could be reposited into the vagina easily by self-manipulation. It was not associated with any difficulty in passing urine or defecation. The mass did not interfere with bowel and bladder functions. There was no associated history of pain/dyspareunia/discharge per vaginum/chronic cough/chronic constipation or any associated menstrual problems. There was no history of episiotomies or perineal surgeries but there was history suggestive of perineal lacerations during deliveries in the past.

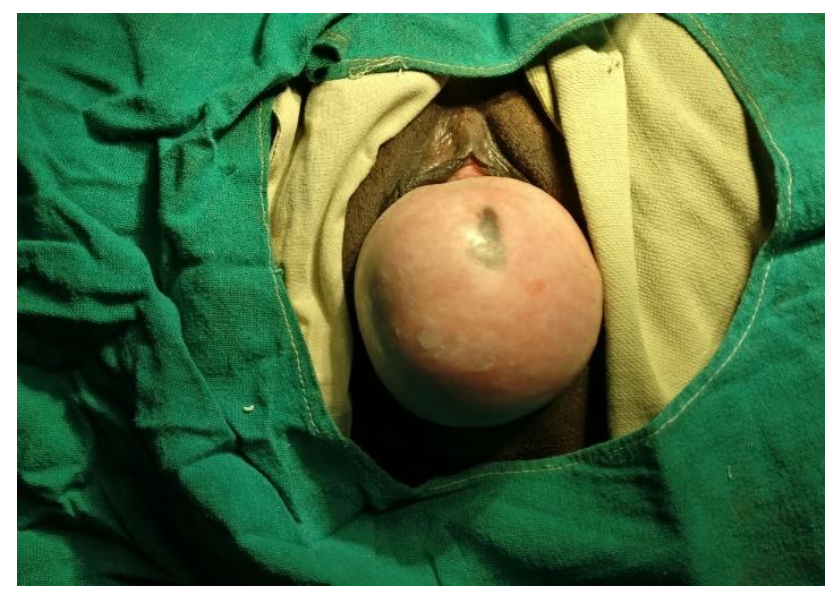

Figure 1: The vaginal cyst of the patient, as observed on examination under anaesthesia.

On examination, she was a thin built, moderately nourished lady. Her general and systemic examination was otherwise unremarkable, and abdomen was soft. On per speculum examination there was a large $7 \times 6 \mathrm{~cm}$ tense bulge seen on posterior vaginal wall, around $3 \mathrm{~cm}$ away from posterior fourchette. However, it did not obliterate the posterior fornix. It was cystic, non-tender, with normal overlying mucosa and obliteration of rugosities. Cough impulse test was negative. On bimanual pelvic examination, upper limit of the swelling could be reached. Per rectal examination ruled out rectocele and confirmed it to be a vaginal cyst with its wall felt separately from rectal mucosa. Trans-illumination test did not show any prolapsed bowel. Also, uterus was anteverted and normal in size, firm in consistency, freely mobile with both fornices free.
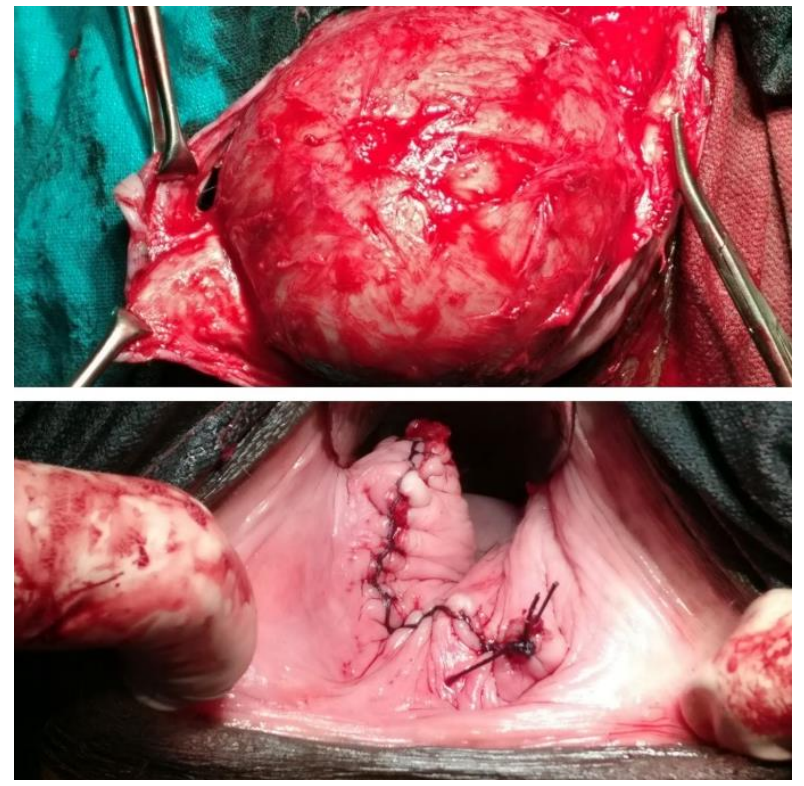

Figure 2: Per-operative pictures of the cyst- surgical excision done, cyst enucleated and wall sutured meticulously.

Blood biochemistry was normal. Due to the pelvic location of the mass, a CA-125 was done. Patient underwent abdominal ultrasonography which revealed a large unilocular hypoechoic cystic area measuring 7x6 $\mathrm{cm}$, anterior to rectum, with diffuse small variable echodensities, besides normal uterus and ovaries measuring. No vascularity was seen within it. Pap smear was negative for intraepithelial lesion or malignancy.

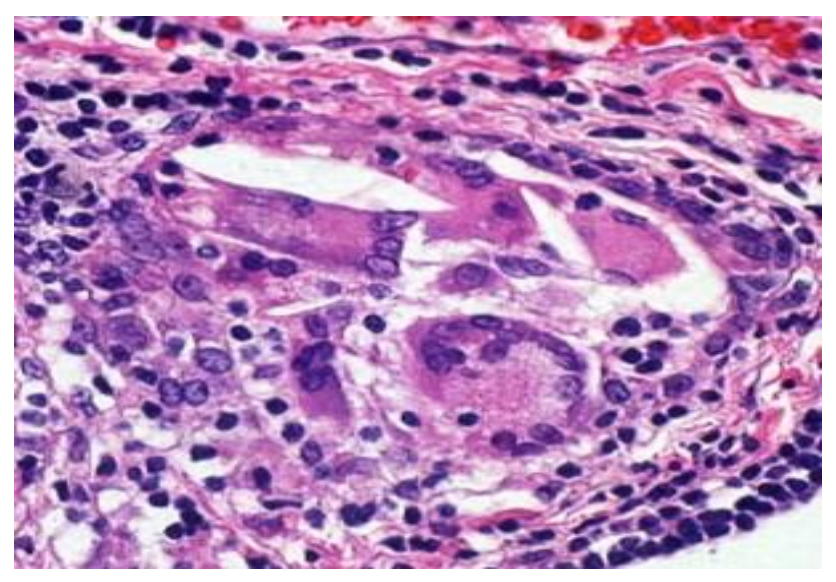

Figure 3: Histopathological slide confirmatory of the inclusion cyst showing smooth vaginal cyst with lining of stratified squamous epithelium.

Cyst wall excision was planned, and patient was operated under regional anaesthesia. Dilute vasopressin was injected into the skin overlying the cyst and a midline vertical incision was given over vaginal mucosa over the cyst; mucosa was separated by blunt and sharp dissection. Care was taken to avoid rectal injury during dissection. Whole cyst was excised intact from the surrounding tissue. Redundant mucosa was trimmed, and vaginal wall 
was repaired with tension free sutures. Post-operative period was uneventful, and patient was discharged on $4^{\text {th }}$ day of surgery in satisfactory condition.

Gross examination showed a greyish- brown, encapsulated, globular, cystic, soft tissue swelling of size $7 \times 6 \mathrm{~cm}$. On cut section it was filled with yellowish pultaceous material. Cyst wall thickness was $0.1 \mathrm{~cm}$ Histopathological examination described inner surface of the cyst as smooth and lined by stratified non-keratinized squamous epithelium. These findings were suggestive of squamous inclusion cyst of vagina.

Since discharge, patient has been under routine follow up, convalescing well, with no fresh complaints till the time of writing the paper, one year post surgery.

\section{DISCUSSION}

Large vaginal cysts are infrequent, detected mostly as benign fluid filled lesions located on the vaginal wall. The peak incidence is between $21-40$ years. ${ }^{1,2}$ the case described was in a perimenopausal woman, which was different from previous accounts in literature. ${ }^{1-11}$

The cysts are classified according to their lining epithelium into following types: mullerian cysts (30\%), Bartholin cysts $(27.5 \%)$, epidermal inclusion cysts $(25 \%)$, Gartner duct cysts $(12.5 \%)$, endometroid cysts $(2.5 \%)$, unclassified cysts $(2.5 \%))^{1,3,4,10}$ If a vaginal cyst does not have a lining epithelium then it could be classified as simple cyst. Vaginal cyst could be an embryological derivative, ectopic inclusion tissue or may be due to urological abnormality.

Any benign or malignant process affecting or growing near the pilo-sebaceous unit may lead to occlusion or impingement of the follicular ostia with subsequent formation of a cyst. Inclusion cysts of vagina are usually small cysts arising from epidermal inclusions of tags of mucosa during healing process or surgical repair of perineal lacerations. These cysts are easily recognised as they are usually found at the site of episiotomies, previous repair or trauma. ${ }^{1,6,10,11}$ Epidermal inclusion cysts are often caused by entrapped epithelium following trauma or persistent abnormal congenital epithelial remnants during fetal growth and development. They might occur as a late complication of female genital circumcision. $^{8-10}$

Although most patients with epidermal inclusion cysts are asymptomatic but few may come up with complaints of mass in the vagina, as was in the index case. Larger cysts cause vaginal pressure or heaviness and protrusion of mass outside the vagina. Rarely an abscess can develop causing symptoms like deep dyspareunia, chronic pelvic pain and painful defecation; some women with anterior/ anterolateral cysts may develop stress urinary incontinence or obstructive urinary symptoms. Secondary infection in such cysts may also lead to
Discharge of a foul-smelling cheese-like material, pelvic pain, dyspareunia, dysmenorrhea, vaginal discharge, bleeding or dyschezia. ${ }^{8,9}$ In the uncommon event of malignancy, rapid growth, friability, and bleeding may be reported. ${ }^{1,8-10}$

Differentiating such cysts is often necessitated from other commoner encountered ones for planning treatment. Site and number of vaginal cyst primarily aids in this; mullerian cysts are typically single and located anterolaterally. Gartner duct cysts and skene duct cysts are anterior or antero-lateral in position. Bartholin cysts are located in the posterior lateral introitus, medial to the labia minora at the site of Bartholin glands.

Dermoid cyst may be found in the mid line posteriorly. Vaginal endometriotic cysts are found along the posterior vaginal fornix and usually associated with endometriotic vaginal implants and pelvic endometriosis. They produce tender, small to medium sized cysts which are mucoid and brown or black in colour. Most of the vaginal cysts present as single cystic lesion but sometimes they may be multifocal also. Epidermal inclusion cysts are usually located in posterior vaginal wall at the site of perineal injury, as was found in the present case.

MRI is helpful in assessing the number, course and anatomical position of the vaginal cysts. ${ }^{10,11}$ Defecography is also helpful in differentiation of posterior vaginal cyst from rectocele. ${ }^{1,6,10-11}$ However, in the narrated case, MRI, though advised, was not done, as patient belonging to lower socioeconomic status could not afford the same.

Managing such cysts often pose a dilemma. Correct clinical identification of a cyst is an essential prerequisite for satisfactory treatment. Small and asymptomatic inclusion cysts could be left under observation, but when large or causing symptoms, as in the present case, surgical excision is the rule. ${ }^{9-11}$

Recurrence of such cyst after aspiration is common, which is rare after excision. Some cysts may regress or subside on their own in due course of time. ${ }^{6,7}$ Sitz bath may help in spontaneous rupture of the cysts in few cases. Post-surgical wound site infection is a potential complication. However, no such recurrence or postoperative complication was observed in the described case.

\section{CONCLUSION}

Giant vaginal cysts have an infrequent occurrence. They are often categorized according to the epithelial lining. Owing to their size, such bulky cysts can imitate cystocele /enterocele. Conscientious clinical examination, bolstered with relevant investigations can delineate the diagnosis. Surgical dissection is the rule, taking caution in avoiding bladder/bowel injury. 


\section{ACKNOWLEDGMENTS}

Authors would like to thank the patient, who besides having experienced this rare condition, allowed us to evaluate her in detail for a better comprehension of the clinical entity.

Funding: No funding sources Conflict of interest: None declared

Ethical approval: The study was approved by the Institutional Ethics Committee

\section{REFERENCES}

1. Unnisa S, Rao SB, Rasquinha VC, Rajagopal K, Prathashwini. Unusual case of posterior vaginal wall cyst. Int J Biomed Adv Res. 2013;04(03):211-3.

2. Sahnidt WN. Pathology of the vagina-vaginal cysts. In: Fox H, Wella M (eds). Haines and Taylor Obstetrical and Gynecological Pathology, 5th edn. New York:Churchill Livingstone;2003;1:180-3.

3. Rashmi SA, Agarwal N, Guleria K, Yadav P. Vaginal mullerian cyst presenting as enterocele. J Obstet Gynecol. 2009 Jan;59:74-6.

4. Junaid TA, Thomas SM. Cysts of vulva and vagina: a comparative study. Int $\mathbf{J}$ Gynaecol Obstet. 1981;19:239-43.

5. Hoffman, Schaffer, Schorge. congenital vaginal cysts. Williams's gynaecology, $2^{\text {nd }}$ edn. Mc Graw Hill Medical;2009:495.
6. Jayaprakash S, Lakshmidevi M. A rare case of posterior vaginal wall cyst. BMJ Case Reports. 2011 Jul 4;2011:bcr0220113804.

7. Kondi-Pafiti A, Grapsa D, Papakonstantinou K, Kairi-Vassilatou E, Xasiakos D. Vaginal cysts: A common pathological entity revisited. Clin Exp Obstet Gynecol. 2008:35:41-4.

8. Dun EC, Ackerman C, Cutler A, Lakhi NA. Excision of an epidermal inclusion cyst: correction of a longterm complication of female genital circumcision. Am J Obstet Gynecol. 2016 Jun;214(6):758-e1.

9. Dagdeviren H, Helvacioglu C, Kanawati A, Kaya C, Cengiz H. Posterior vaginal wall cyst mimicking rectocele. J Preg Child Health. 2017;4:306.

10. Pradhan J, Tobon H. Vaginal cysts: a clinicpathological study of 41 cases. Int J Gynecol Pathol. 1986;5:35-46.

11. Cil AP, Basar MM, Kara SA, Atasoy P. Diagnosis and management of vaginal mullerian cyst in a virgin patient. Int Urogynecol J. 2008 May;19(5):735-7.

Cite this article as: Garg D, Marwah S, Sharma R, Salhan S. A large posterior vaginal wall cyst simulating rectocele: an account of an unusual perplexing case. Int J Reprod Contracept Obstet Gynecol 2018;7:1224-7. 